\title{
Modeling eutrophication and oligotrophication of shallow-water marine systems: the importance of sediments under stratified and well-mixed conditions
}

\author{
Karline Soetaert · Jack J. Middelburg
}

Published online: 21 April 2009

(C) The Author(s) 2009. This article is published with open access at Springerlink.com

\begin{abstract}
A one-dimensional model that couples water-column physics with pelagic and benthic biogeochemistry in a 50-m-deep water column is used to demonstrate the importance of the sediment in the functioning of shallow systems, the eutrophication status of the system, and the system's resilience to oligotrophication. Two physical scenarios, a well-mixed and a stratified water column, are considered and both are run along a gradient of increasing initial pelagic-dissolved inorganic nitrogen (DIN) concentration. Where the mixed layer extends to the bottom, more nutrients and less light are available for growth. Under low to moderately eutrophic conditions (pelagic DIN $<30 \mathrm{mmol} \mathrm{m}^{-3}$ ), this leads to higher productivity in well-mixed waters, while the stratified system is more productive under highly eutrophic conditions. Under stratification, the build-up of nitrate and depletion of oxygen below the mixed layer does not notably change the functioning of the sediment as a sink for reactive
\end{abstract}

Guest editors: J. H. Andersen \& D. J. Conley

Eutrophication in Coastal Ecosystems: Selected papers from the Second International Symposium on Research and

Management of Eutrophication in Coastal Ecosystems, 20-23 June 2006, Nyborg, Denmark

K. Soetaert $(\bowtie) \cdot$ J. J. Middelburg

Netherlands Institute of Ecology (NIOO-KNAW),

Centre for Estuarine and Marine Ecology,

P.O. Box 140, 4400 NT Yerseke, The Netherlands

e-mail: k.soetaert@nioo.knaw.nl nitrogen. In sediments underlying well-mixed waters, sedimentary denitrification, fueled mainly by in situ nitrification, is slightly more important $(8-15 \%$ of total benthic mineralization) than under stratified waters (7-20\%), where the influx of bottom-water nitrate is the most important nitrate source. As a consequence of this less efficient removal of reactive nitrogen, the winter DIN concentrations are higher in the stratified scenario. The model is used to estimate the long-term benefits of nutrient reduction scenarios and the timeframe under which the new steady-state condition is approached. It is shown that a 50\% reduction in external nitrogen inputs ultimately results in a reduction of $60-70 \%$ of the original pelagic DIN concentration. However, as the efflux of nitrogen from the sediment compensates part of the losses in the water column, system oligotrophication is a slow process: after 20 years of reduced inputs, the pelagic DIN concentrations still remain $2.7 \mathrm{mmol} \mathrm{m}^{-3}$ (mixed) and $3.9 \mathrm{mmol} \mathrm{m}^{-3}$ (stratified) above the ultimate DIN concentrations.

Keywords Benthic-pelagic coupling . Model · Nitrogen cycle · Denitrification · Eutrophication · Oligotrophication

\section{Introduction}

In shallow aquatic systems, the sediments are important sites of organic matter degradation and 
secondary production (Jørgensen, 1983). On the shelf, the benthic contribution to total respiration is estimated to be 40-50\% (Heip et al., 1995; Wollast, 1998; Alongi, 2005), and this fraction generally increases with decreasing water depth. Through benthic mineralization, an important part of the nutrients, for example nitrogen, taken up by pelagic and benthic algae, is recycled. However, sediments not only return nutrients, but a proportion gets stored or is simply removed from the ecosystem. Denitrification is the most important benthic removal process for nitrogen, accounting for about a third to a half of the total nitrogen loss of the ocean (Christensen, 1994; Middelburg et al., 1996). Sediments also temporarily store organic matter and nutrients both in the long term and in the short term (Soetaert et al., 2000). Nitrogen is removed by the burial of refractory organic material and dissolved inorganic nitrogen through sediment accretion, and by adsorption of ammonium to the sediment.

On short time scales, transient (seasonal) storage of nutrients may cause a mismatch between watercolumn nutrient demand and supply, and thus directly affect pelagic production. On longer time scales, nutrients that have accumulated in the sediments because of historical eutrophication may be released when the conditions in the water column are altered, for example, by reduced nutrient loadings. Thus, sediment-water interactions in shallow coastal waters have an important effect on primary production and ecosystem dynamics (Middelburg \& Soetaert, 2005).

In many shallow marine systems worldwide, increases in industrial, agricultural, and domestic activities have led to massive inputs of nutrients over the past centuries (e.g., van Raaphorst \& de Jonge, 2004; Soetaert et al., 2006). Consequently, reduction in nutrient loadings has been undertaken to reverse the trend of increasing eutrophication. However, oligotrophication did not always lead to the desired reduction in the intensity of algal blooms (Kemp et al., 2005), and the effects are not necessarily the same for different nutrients (Soetaert et al., 2006).

Predicting the effects of changes in nutrient input on the ecosystem is difficult. The lack of understanding is at least partly due to limited knowledge on the impact of benthic nutrient cycling on the resilience of ecosystems to eutrophication. For lakes, it has been shown that the effects of such internal loading are to delay the ecosystem recovery, postponing the establishment of a new equilibrium by about 10-20 years (Jeppesen et al., 2005).

In many regions of the world, where high primary production coincides with low degrees of watercolumn mixing, eutrophication leads to recurrent hypoxia or anoxia (Officer et al., 1984). The anoxic waters possess unique chemical and biological characteristics, such as unusually high concentrations of dissolved inorganic nutrients and reduced substances, and the occurrence of processes is typically associated with anoxic sediments, such as denitrification (Naqvi et al., 1982), Anammox (Kuypers et al., 2005) or nitrous oxide formation (de Bie et al., 2002). The peculiar characteristics of anoxic bottom waters and the loss of metazoan benthic life (Kemp et al., 2005; Rabalais, 2005) have drastic consequences on ecosystem functioning, the oxidative status of the released nutrients, and the balance of nutrient release or retention in the sediment (Kemp et al., 1990; Childs et al., 2002).

Predicting the response of ecosystems to changing nutrient loads requires the development of models with appropriate descriptions of the benthic-pelagic coupling. Such models could also serve as a basis for setting goals for nutrient reduction (e.g., Cerco \& Cole, 1993) or for predicting effects of global change. By increasing the water temperature and river runoff, global change is likely to prolong stratification, reduce mixing, increase primary production, and decrease the solubility of oxygen, with important consequences on the extent of anoxic zones and benthic respiration (Justic et al., 2005). How this will affect the susceptibility of the system to eutrophication or the resilience to oligotrophication remains unclear.

This article reports on the use of a one-dimensional coupled pelagic-benthic model (Soetaert et al., 2000, 2001; Middelburg \& Soetaert, 2005) to estimate the impact of sediments on the biogeochemical functioning of a shallow-water marine system. Two scenarios were run: one where the water column remains completely mixed and oxic, and the other where the water column becomes stratified during summer and anoxic conditions develop. These scenarios demonstrate how the sediment affects the resilience of the ecosystem to eutrophication and oligotrophication under these two conditions. 


\section{Materials and methods}

\section{Model description}

The model couples three submodels that describe the physics of the water column, the pelagic biogeochemistry, and the sediment diagenetic properties (Fig. 1). The model was described extensively by Soetaert et al. (2000, 2001) and Middelburg \& Soetaert (2005); these articles should be consulted for model equations and for parameter values. The pelagic model has 50 equally sized vertical layers in a 50-m-deep water column, with 100 layers in the sediment that progressively increase in thickness from $0.1 \mathrm{~cm}$ at the sediment surface to $2 \mathrm{~cm}$ at depth. The total sediment depth covered is about $60 \mathrm{~cm}$.

Water-column turbulence and sinking

Vertical water-column mixing in the model is based on the $\mathrm{k}-\varepsilon$ turbulence-closure formulation of Gaspar et al. (1990). The air-sea heat exchange is forced by $3-\mathrm{h}$
Fig. 1 Schematic representation of the three coupled submodels describing the watercolumn physics (left), water-column biogeochemistry (right), and sediment biogeochemistry (below)
Wind, air temperature, air density, pressure, solar radiation

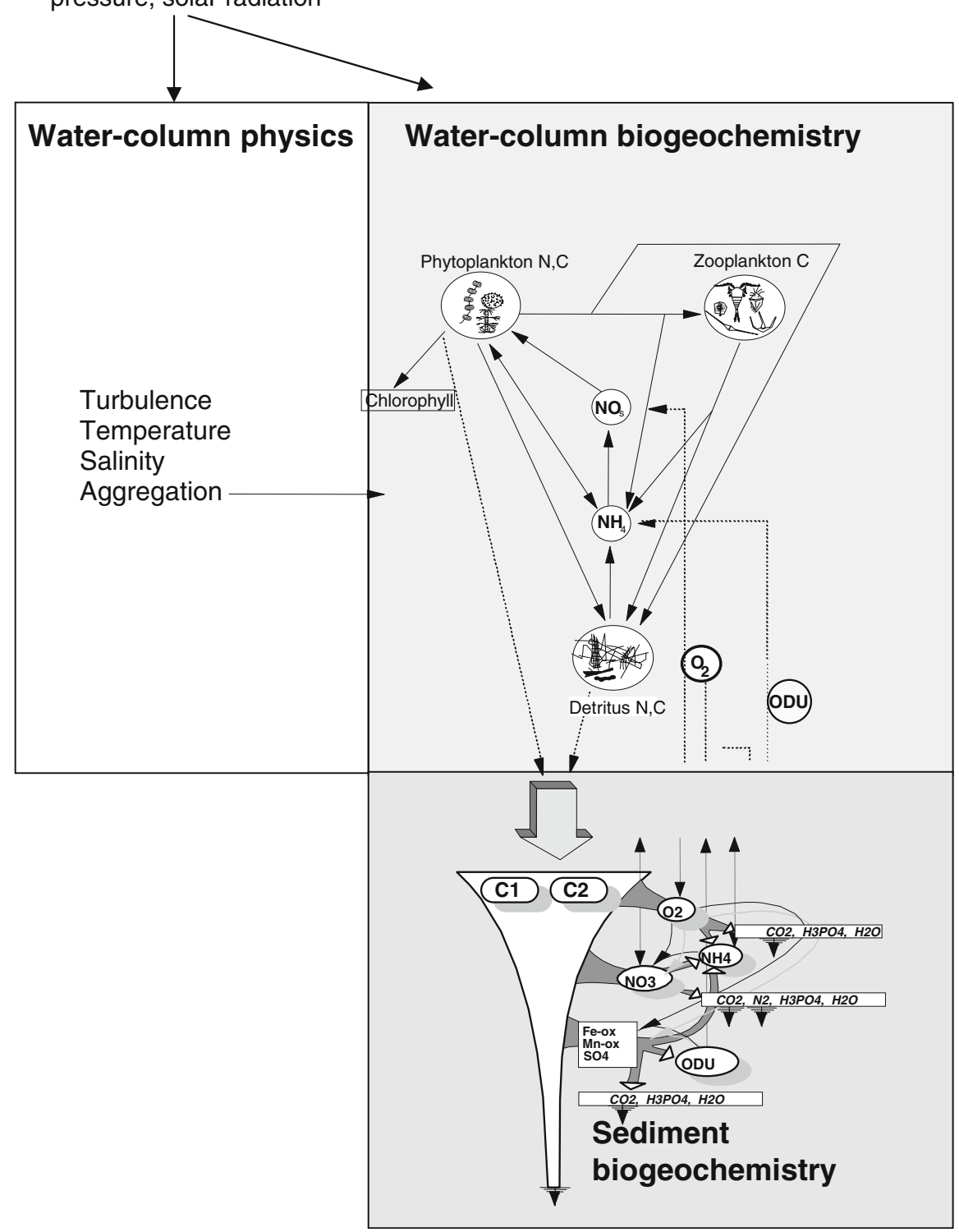


atmospheric data, as used by Soetaert et al. (2001) and Middelburg \& Soetaert (2005), and representative for a temperate area (Goban spur, NE Atlantic). In order to increase the seasonality in the modeled water temperature, the seasonality in the air temperature was increased by $50 \%$. Solar radiation was modeled as a sine wave, on which a random perturbation was added (Soetaert et al., 2000); $50 \%$ of the light was assumed to be in the infrared and the remaining in the photosynthetically active radiation (PAR).

Two physical scenarios were run:

1. The mixed scenario: Here, atmospheric conditions and the tidal pressure gradient are the only external forcing applied to the model.

2. The stratified scenario: In addition to the atmospheric and tidal forcing, input of brackish water (salinity $S^{b}=25$ ) on top and saline water (salinity $S^{S}=35.5$ ) near the bottom provides a stabilizing factor that reduces mixing. The extra fluxes mimic the outflow of estuarine water on the top of marine waters. It is achieved by nudging, using a velocity $\gamma$ of $0.24 \mathrm{~m} \mathrm{~d}^{-1}$ as follows:

$$
\begin{aligned}
-\left.K z \frac{\partial S}{\partial z}\right|_{0} & =@-\left(S_{0}-S^{b}\right) \cdot \gamma \text { and }-\left.K z \frac{\partial S}{\partial z}\right|_{50} \\
& =-\left(S_{50}-S^{S}\right) \cdot \gamma,
\end{aligned}
$$

where $S$ is the salinity, $z$ is the depth, 0 and 50 are the air-sea and sediment-water interfaces, respectively, $K z$ is the vertical mixing coefficient, and @ is the atmospheric salinity "flux" due to evaporation.

\section{Pelagic biogeochemical model}

As algae can store excess dissolved inorganic nitrogen, their nitrogen and carbon allocation are uncoupled (Tett \& Droop, 1988), which results in an explicit description of phytoplankton carbon and nitrogen and variable nitrogen to carbon ratios. Photoadaptation is approximated by assuming that the algal chlorophyll:nitrogen (Chl:N) ratio linearly and positively depends on the algal nitrogen:carbon $(\mathrm{N}: \mathrm{C})$ ratio. One class of zooplankton, expressed in nitrogen units, is modeled. It grazes on phytoplankton, using simple Monod-type saturation. Zooplankton mortality is expressed as a second-order closure term, which increases strongly when the oxygen concentration is low. The constant stoichiometry of the zooplankton is maintained by excess excretion or respiration to account for imbalances between nitrogen or carbon in its food and in zooplankton tissues. The bacterial loop is not resolved, but it is assumed that the mineralization of organic nitrogen and organic carbon proceeds at a first-order rate, where nitrogen decays more rapidly than carbon. Detritus mineralization proceeds unlimited by the oxygen concentration. In oxic conditions, oxygen is consumed; however, when oxygen is depleted, the mineralization process produces an undefined anoxic substance (oxygen demand units, ODU). This description is similar to that for the sediments (see below). Upon restoration of the oxic conditions, the ODU are re-oxidized, consuming one mole of oxygen per mole of ODU. Nitrate and ammonium are the only nutrients considered; ammonium is the preferred source of nitrogen for the algae. It is converted to nitrate (water column nitrification) at a low rate.

The sinking rate of detritus is calculated by the aggregation model of Kriest \& Evans (1999). In contrast, algae sink with a constant velocity. All pelagic rates are temperature dependent. Photosynthetically active radiation is described by short- and long-wave radiation, with a different background extinction coefficient, to which a chlorophyll-dependent extinction is added. With the light settings used, the yearly averaged depth of the $1 \%$ level of daylight penetration is around $25 \mathrm{~m}$, which is consistent with measurements in the North Sea (Visser, 1969 in Otto et al., 1990).

Oxygen is the only biogeochemical substance exchanged across the air-sea interface.

\section{Sediment biogeochemical model}

Diagenetic models (Boudreau, 1996) are biogeochemical descriptions of sedimentary systems that take into account the complexity of the sediments. The diagenetic model used, OMEXDIA (Soetaert et al., 1996), represents the sedimentary $\mathrm{C}, \mathrm{N}$, and oxygen $\left(\mathrm{O}_{2}\right)$ cycles. It combines the description of solid (two organic matter pools) and solute (oxygen, nitrate, ammonium, and ODU) species. The organic matter degradation in the sediment follows the standard two-compartment type of organic matter consumption, with orders-of-magnitude differences in decay rates and different N:C ratios. Mineralization releases ammonium which may subsequently be 
re-oxidized to nitrate (nitrification), flux to bottom water, or be adsorbed onto the solid phase. From the sediment-water interface to depth into the sediment, the oxidation of organic matter proceeds first using oxygen as an electron acceptor. In deeper, lowoxygen layers, nitrate is used for mineralization (denitrification) until nitrate is exhausted, below which organic matter oxidation is driven by the reduction of manganese $(\mathrm{Mn})$ and iron $(\mathrm{Fe})$ oxides, sulfate $\left(\mathrm{SO}_{4}\right)$, and finally by methane fermentation. None of these anoxic processes are separately modeled; rather, it is assumed that the mineralization of organic matter via these pathways is not limited by oxidants, such that the electron acceptors that take part in anoxic mineralization need not be described. Given the high concentrations of $\mathrm{SO}_{4}{ }^{2-}$ in marine pore waters, this is a valid assumption. However, during anoxic mineralization, $\mathrm{Fe}$ and $\mathrm{Mn}$ ions, sulfide, and methane are formed and released to the interstitial waters where they may flux upward into the oxic zone to be re-oxidized. As this oxygen consumption may constitute a significant fraction of the total oxygen consumption in the sediment, it needs to be taken into account. Thus, in OMEXDIA, the anoxic mineralization produces a reduced substance, termed ODU, which constitutes the sum of Fe and $\mathrm{Mn}$ ions, sulfide, and methane. When oxygen is present, the ODU is re-oxidized; one mole of oxygen is consumed for the re-oxidation of one mole of ODU. The interplay between particles and dissolved substances is incorporated by imposing a gradient in porosity (Ф), declining exponentially from 0.95 at the sediment-water interface to 0.75 at $3 \mathrm{~cm}$ depth, below which it remains constant; such a porosity gradient is typical for muddy sediments.

In analogy with water-column processes, sedimentary constituents are affected by mixing and advection processes. A constant sediment accretion rate is assumed. The solid phase in muddy sediments is mixed mainly by the crawling and feeding activity of animals, which is parameterized by a bioturbation coefficient (Db). As animal life is restricted to the upper layer of the sediments, the bioturbation coefficient is assumed constant in the upper, bioturbated layer, below which it declines exponentially. Solute mixing in mud occurs essentially via molecular diffusion, corrected for the tortuous path that molecules need to take, and may be increased by the ventilation activity of benthic animals. In
OMEXDIA, animal ventilation is represented by the simplest formulation, that is, as an enhanced diffusion. Thus, diffusion is increased by a multiplication factor, which varies with depth into the sediment in a similar manner as the bioturbation coefficient.

\section{Sediment parameters}

The biogeochemical rate parameters and half-saturation or inhibition constants from the original OMEXDIA model (Soetaert et al., 1996) were left unaltered. As the diagenetic model explicitly deals with biogeochemical processes, the effect of benthic animals must be parameterized. In general, benthic animals influence biogeochemical cycles in three ways: (1) through their metabolism, respiration, and excretion, they convert organic matter to inorganic form (dissolved nutrients and carbon dioxide) and consume oxygen; (2) by their crawling and feeding activity, they mix the sediment (bioturbation); and (3) some organisms pump bottom water through their burrows thus increasing the exchange rate of solutes between the water column and the sediment (bio-irrigation).

The respiration of higher organisms and bacteria was incorporated as a first-order decay rate, assuming two pools with largely varying decomposition rates, and using the parameter values as in Soetaert et al. (1996). These settings were the same between the well-mixed and the stratified scenarios. Solid-phase mixing due to animal crawling and feeding activity was modeled as a diffusive process, while the ventilation of the sediment due to burrow irrigation was described as an enhancement of sediment-water exchange over molecular diffusion. The intensity of these processes was considered to differ under wellmixed and stratified conditions. When lasting for long enough periods, anoxia may completely eradicate the larger benthic animals (e.g., Rabalais et al., 2002), and it may take years before significant populations of macrofauna return (Josefson \& Widbom, 1988). In contrast, smaller organisms are less affected and may recover more rapidly upon restoration of oxic conditions (Josefson \& Widbom, 1988). As larger animals contribute most to bioturbation and bio-irrigation, anoxia also affects the degree to which the sediments are mixed or to which water is pumped in the sediment. Mixing intensities in marine sediments were compiled by Middelburg et al. (1997) and they 
fall roughly in the range from 1 to $100 \mathrm{~cm}^{2} \mathrm{yr}^{-1}$ in shallow sediments; for a 50-m-deep station, the geometric and arithmetic mean of bioturbation coefficients are 5 and $25 \mathrm{~cm}^{2} \mathrm{yr}^{-1}$, respectively. For the mixed-case scenario, with permanently oxic bottomwater conditions, an intermediate bioturbation coefficient of $15 \mathrm{~cm}^{2} \mathrm{yr}^{-1}$ was chosen, while for the stratified case, where the water column becomes temporarily anoxic, the bioturbation rate was set an order of magnitude lower $\left(1.5 \mathrm{~cm}^{2} \mathrm{yr}^{-1}\right)$. Mixedlayer depth was assumed to be $5 \mathrm{~cm}$ in the wellmixed scenario and $1 \mathrm{~cm}$ in the stratified scenario. Similarly, the ventilation, which triples the diffusion rate over molecular diffusion in the well-mixed physical scenario, is turned off under stratification.

\section{Submodel coupling}

The coupling between the physical and biogeochemical pelagic models was done off-line. The interaction between benthic and pelagic biogeochemistry is twodirectional; therefore, these submodels are coupled on-line. Organic matter, settling from the water column onto the sediment, adds to sediment organic matter, assuming a fixed proportion of rapidly and slowly decaying organic matter. The pelagic model provides the bottom-water concentrations of oxygen, nitrate, ammonium, and ODU, which constitute the upper boundary condition of the sediment model. The latter then estimates the sediment-water exchange flux, which is used to adjust bottom-water concentrations. It is also assumed that the temperatures in sediment and bottom water are equal.

Sedimentary denitrification removes fixed nitrogen from the system. If the model is run in steady-state (with the same annual dynamics repeated), this nitrogen loss should be compensated by lateral influx. Soetaert et al. (2000) tested several scenarios to model this flux and concluded that the manner in which this nitrogen was effectively returned had only a marginal effect on the system's dynamics. For the runs reported here, a flux of ammonium was imposed to the bottom water, instantaneously compensating the $\mathrm{N}_{2}$ loss.

\section{Solving the coupled model}

The coupled model was implemented in the simulation environment FEMME (Soetaert et al., 2002), which addresses the technical aspects of the modeling.

Owing to the large differences in spatial scales, of the order of $1 \mathrm{~m}$ in the pelagic model, and from $1 \mathrm{~mm}$ to $2 \mathrm{~cm}$ in the sediment model, the numerical properties of pelagic and benthic submodels are very different. The pelagic model was solved by simple explicit (Euler) integration, except for transport which was approximated by a fully implicit integration scheme. The time-step chosen for the pelagic model was $7.5 \mathrm{~min}$. In the benthic model, the dynamics of the different substances proceed at orders-of-magnitude different time scales, from a fraction of a second for oxygen in some sediment layers to the order of years for the low-reactive organic matter components. This leads to a stiff set of equations that was solved with an implicit integration routine that adapts the time-step to the model dynamics, in order to preserve a pre-set tolerance level (Brown et al., 1989).

The coupled model then proceeded with common time-steps of $1 \mathrm{~h}$, during which the pelagic model took eight steps, and the diagenetic model took a variable number of steps (depending on the model dynamics). During the hourly integration, the average deposition of organic matter and the average bottomwater concentrations, as estimated during the previous hour from the pelagic model, were imposed onto the sediment upper boundary. Similarly, the average sediment-water nutrient, oxygen, and ODU fluxes, as estimated by the diagenetic model from the previous hourly integration, were used to update the bottomwater concentrations. This mode of coupling is very efficient, but introduces a time lag of $1 \mathrm{~h}$ between both submodels. As the interest of this work was mainly in much longer time scales, this artificial lag was insignificant. Reducing the common time-step did not have any noticeable effect on the model outcome.

Owing to the large difference in time scales of the benthic model, this part must be carefully initialized, to avoid a too long spin-up time before the sediment model is in equilibrium with the pelagic dynamics (and vice versa). Correct initialization of the slowest reactive fraction of organic matter is especially critical. This is the fraction of organic matter that partly escapes below the bioturbated area, where it is moved only by sediment advection. It would take many thousands of years of runtime before 
concentrations of this organic matter fraction have built up in equilibrium at these depths. In order to avoid such long spin-up, the following procedure was used. First, the pelagic model was run without adding the diagenetic model. Instead, a zero-flux lower boundary was assumed (Soetaert et al., 2000), meaning that all organic matter deposited is immediately mineralized and provokes an equivalent source of nitrogen and sink of oxygen. Based on this run, an annual mean organic matter deposition rate and a mean bottom-water concentration were calculated. These were then used to initialize the diagenetic model by generating steady-state concentration versus depth profiles under these conditions. This is done by solving for the root of the 600 non-linear equations. After this initialization, the model was run for at least 5 years, and convergence to equilibrium tested. Only the results from the last year are shown.

Both physical scenarios (mixed and stratified) were applied in a range of initial concentrations of DIN in the water column $(5,10,15,20,25,30,50$, 100 , and $200 \mathrm{mmol} \mathrm{m}^{-3}$ ). In order to run the full model for 1 year of simulation, it takes about $2.5 \mathrm{~min}$ on a Pentium 4, $3 \mathrm{GHz}$ personal computer.

\section{Results}

Physical properties

Figure 2 displays an annual cycle of the modeled temperature field and the turbulent diffusion coefficient as generated by the turbulence-closure model for the two physical conditions. Without extra stabilization (the mixed-case scenario), the 50-mdeep water column remains almost completely mixed, except the onset of summer where the water column stratifies slightly (Fig. 2C) and a temperature gradient of about $1^{\circ} \mathrm{C}$ from top to bottom emerges (Fig. 2A). In contrast, when including a brackishwater flux near the surface and a flux of saline water near the bottom, stratification starts in spring and lasts throughout summer (Fig. 2D). The maximum difference between bottom and surface temperatures is $9^{\circ} \mathrm{C}$ (Fig. 2B).

\section{Water-column biogeochemistry}

In Fig. 3, the changes in nitrate and oxygen concentrations during an annual cycle and vertically in the
Fig. 2 Spatiotemporal plot of water-column temperature $(\mathbf{A}, \mathbf{B})$ and diffusion coefficients $(\mathbf{C}, \mathbf{D})$ for the mixed $(\mathbf{A}, \mathbf{C})$ and stratified (B, D) conditions
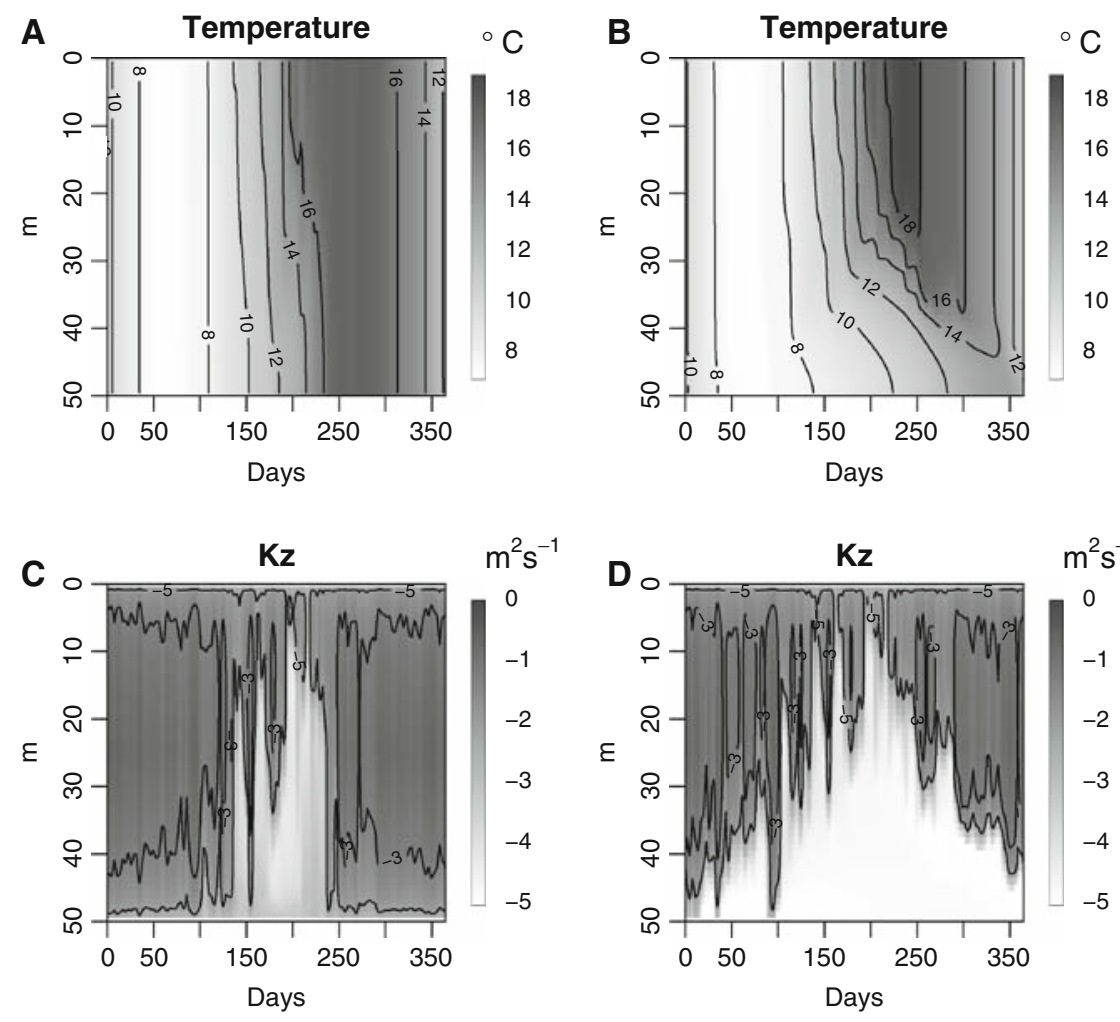
water column are depicted for a water-column DIN concentration in winter of $10 \mathrm{mmol} \mathrm{m}{ }^{-3}$. This is a typical condition for temperate coastal systems such as the North Sea.

The development of the phytoplankton bloom, as light intensity increases in spring, depletes the mixedlayer nitrate (Fig. 3C, D) until it is entirely consumed in summer. This depletion occurs earlier (around day 100; Fig. 3D) in the stratified compared to the wellmixed case (day 130, Fig. 3C). The organic matter produced sinks toward the bottom and is mineralized at greater depth. During this process, oxygen is consumed and nutrients are released. Under stratified conditions, this first leads to a strong decrease and ultimately complete depletion of oxygen and the water column becomes anoxic below the mixed-layer depth (Fig. 3B). Also, a sub-surface nitrate peak emerges after the exhaustion of nutrients in the mixed layer (Fig. 3D). Similar results were obtained in a modeling study of the Louisiana-Texas shelf in the Gulf of Mexico (Chen et al., 1997).

If the winter nutrient concentration of the water is increased from $10 \mathrm{mmol} \mathrm{m}^{-3}$ (Fig. 3C, D) to $30 \mathrm{mmol} \mathrm{m}^{-3}$ (Fig. 4A, B), the initiation of nutrient limitation is postponed until a later date. Thus, nitrate is completely exhausted at day 190 and 170 in the mixed and stratified waters, respectively (Fig. 4), which is 60 to 70 days later than depletion in the $10 \mathrm{mmol} \mathrm{m}^{-3}$ scenario. This trend continues as the winter DIN concentrations are increased (not shown), except the highest loadings at which exhaustion no longer occurs.

\section{Eutrophication gradient}

The annual algal uptake of DIN and primary production along a gradient of increasing pelagic DIN concentrations are shown in Fig. 5A, B. Higher nutrient concentrations enhance annual primary production by prolonging the production period, and the annual-averaged algal assimilation of DIN and primary production increase until they level off. Under the mixed-case scenario, this occurs at a winter DIN concentration of about $50 \mathrm{mmol} \mathrm{m}^{-3}$, where primary production reaches values of $390 \mathrm{~g} \mathrm{C} \mathrm{m}^{-2}$ $\mathrm{yr}^{-1}$, while under stratification, the maximum production attained is higher $\left(510 \mathrm{~g} \mathrm{C} \mathrm{m}^{-2} \mathrm{yr}^{-1}\right)$ and this maximum is reached at higher mean DIN concentrations $\left(100 \mathrm{mmol} \mathrm{m}^{-3}\right)$. Stratification has an opposite effect on nutrient and light limitation of
Fig. 3 Spatiotemporal plot of water-column oxygen (A, B) and nitrate $(\mathbf{C}, \mathbf{D})$ concentrations for the mixed $(\mathbf{A}, \mathbf{C})$ and stratified $(\mathbf{B}, \mathbf{D})$ conditions, as modeled for a winter watercolumn DIN concentration of $10 \mathrm{mmol} \mathrm{m}^{-3}$
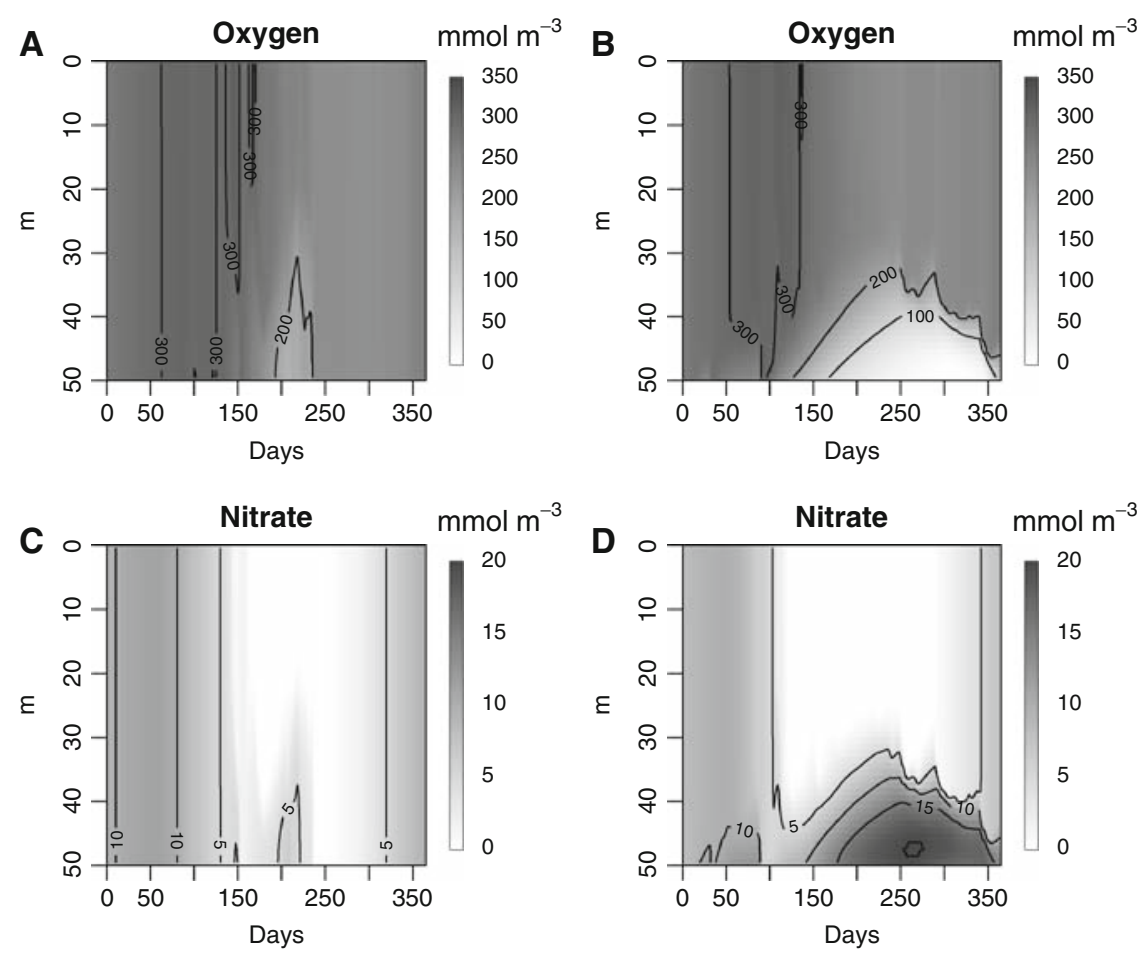
Fig. 4 Water-column nitrate concentrations for the mixed (A) and stratified (B) conditions, as modeled for a winter water-column DIN concentration of $30 \mathrm{mmol} \mathrm{m}^{-3}$
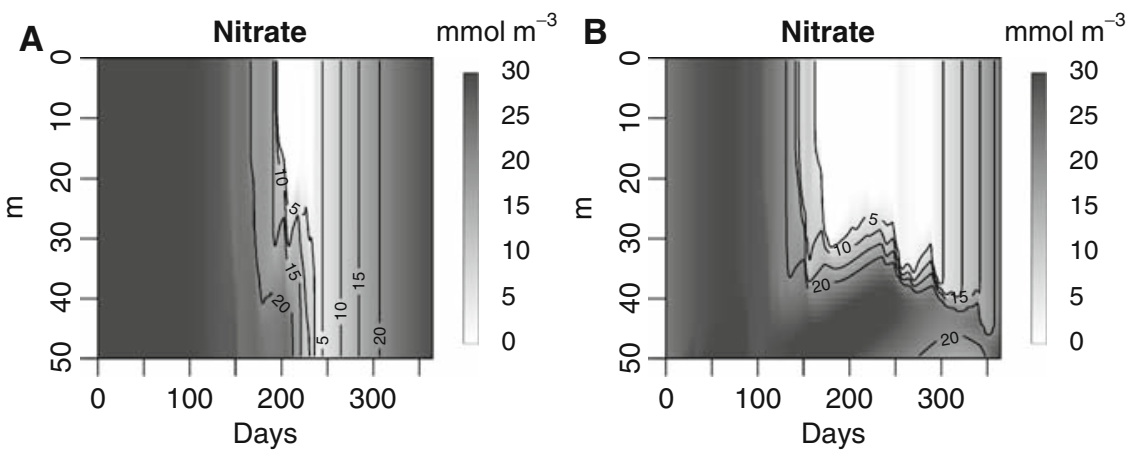

Fig. 5 Algal uptake of dissolved inorganic nitrogen (A) and primary production (B) as a function of increased mean pelagic DIN concentrations for the mixed and stratified scenarios. The top of the diagram indicates where the algae are on average "nutrient limited" or "light limited" for the well-mixed (gray line) and stratified (black line) conditions

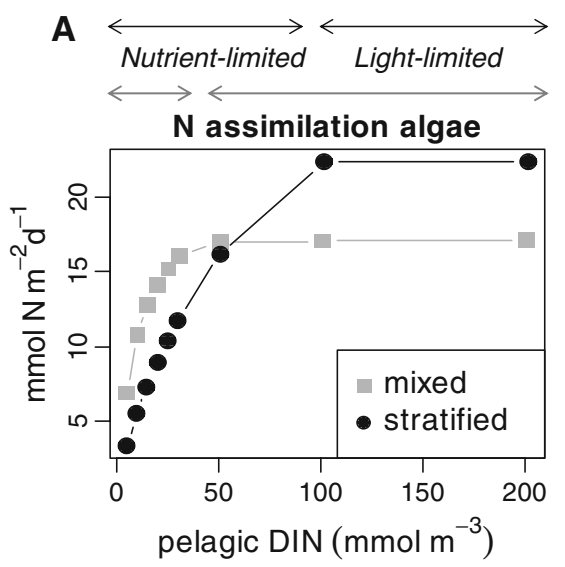

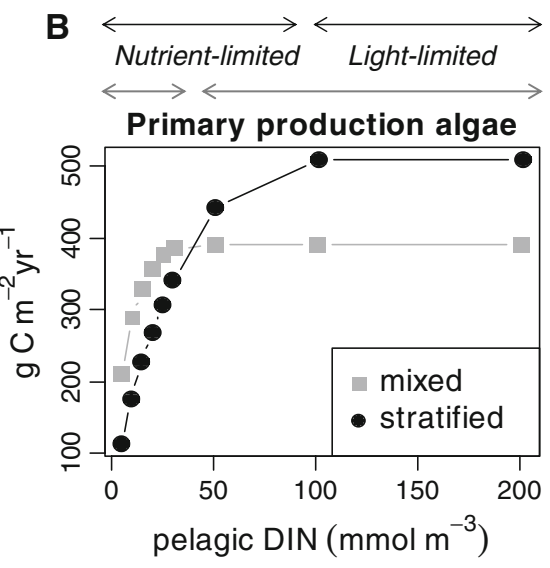

the algae. If algae are mixed from surface to bottom, the average light experienced is less intense and the light limitation is stronger than where mixing is limited from the surface to several meters above the bottom. However, under low mixing, nutrient concentrations build up below the thermocline and remain inaccessible for algal growth.

Therefore, where winter nutrient concentrations are low, algal production in a stratified water column is lower than under well-mixed conditions. At very high winter concentrations, nutrient limitation no longer occurs, and the productivity under stratification surpasses the mixed-water case production, due to the more favorable light conditions.

In the model presented here, the primary production of pelagic DIN concentrations ranging from 5 to $15 \mathrm{mmol} \mathrm{m}^{-3}$ varied from 210 to $325 \mathrm{~g} \mathrm{C} \mathrm{m}^{-2} \mathrm{yr}^{-1}$ under well-mixed conditions, and from 112 to $220 \mathrm{~g} \mathrm{C} \mathrm{m}^{-2} \mathrm{yr}^{-1}$ under stratified conditions (Fig. 5B). This compares well with the estimate of 250-300 $\mathrm{g} \mathrm{C} \mathrm{m}^{-2} \mathrm{yr}^{-1}$ for coastal waters of the North Sea (Joint \& Pomroy, 1993).
Sediment model

The changes in sedimentary nitrate and ammonium concentrations as determined for pelagic winter DIN concentrations of $10 \mathrm{mmol} \mathrm{m}^{-3}$ are illustrated in Fig. 6. In winter, a clear build-up of nitrate can be seen below the sediment-water interface, up to $30 \mathrm{mmol} \mathrm{m}^{-3}$ for the mixed case (Fig. 6A) and $22 \mathrm{mmol} \mathrm{m}^{-3}$ for the stratified case (Fig. 6B). As more oxygen is consumed during summer, the oxygen penetration depth shifts upward, and the nitrate peak becomes less pronounced (mixed case, Fig. 6A) or disappears (stratified case, Fig. 6B). At the same time, ammonium increases at depth in the sediment (Fig. 6C, D).

The sediments underlying the well-mixed water column have higher bioturbation and bio-irrigation rates. As these have a different effect on sediment functioning, both the ammonium and nitrate concentrations are highest under well-mixed conditions. By bio-irrigating their burrows, organisms pump water into the sediment, thus shortening diffusive pathways 
Fig. 6 Spatiotemporal plot of sediment nitrate $(\mathbf{A}, \mathbf{B})$ and ammonium $(\mathbf{C}, \mathbf{D})$ concentrations for the wellmixed (A, C) and stratified (B, D) conditions, as modeled for pelagic winter DIN concentrations of $10 \mathrm{mmol} \mathrm{m}^{-3}$
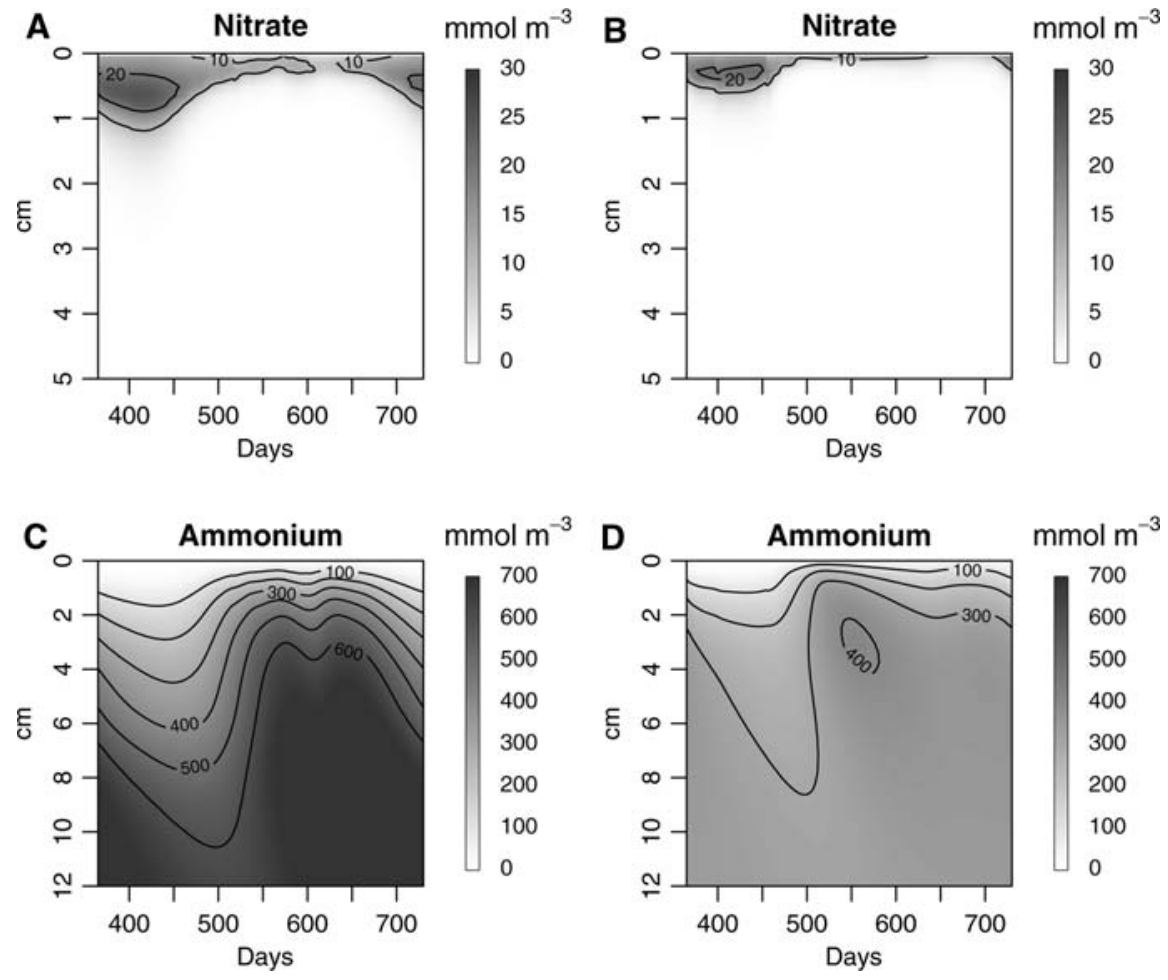

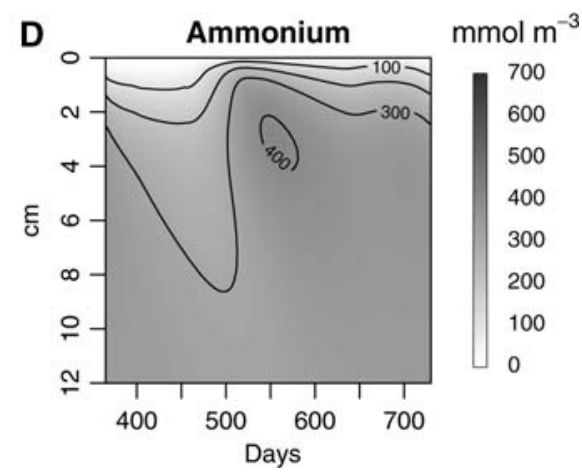

for oxygen in sediments (Meysman et al., 2006); this promotes oxygen-consuming processes such as nitrification. This provides an explanation for the higher concentrations of nitrate in the mixed-case scenario. The build-up of ammonium depends on the amount and the depth of organic matter mineralization. With increasing mixing rates, organic matter deeper into the sediment is decomposed and the pore waters become enriched in ammonium at these depths. Similar behavior has been described for the build-up of phosphate as a function of sediment advection (Van Cappellen \& Berner, 1988). In contrast, as bioturbation in sediments under the stratified water column is reduced, organic matter is mineralized closer to the sediment-water interface. Thus, ammonium is released more superficially, resulting in a stronger initial gradient and therefore a larger efflux to the water column; as a consequence, lower concentrations build up.

The importance of the sediment in the biogeochemical functioning of shallow-water marine systems is illustrated by Fig. 7. A significant fraction of the organic matter decays in the sediment. The relative contribution of the sediment with respect to total system mineralization varies between $44 \%$ and $54 \%$
(Fig. 7A). This corresponds well with literature estimates, which on average are close to a $50 \%$ contribution of benthic mineralization in shallow systems (Heip et al., 1995; Wollast, 1998; Rabouille et al., 2001; Middelburg et al., 2005). With increasing eutrophication, the share of the sediment in system mineralization increases slightly (Fig. 7A), from $44 \%$ to $54 \%$. This is due to a lower efficiency of zooplankton grazing on the algae at high production rates, as the feeding rate of the zooplankton saturates at high algal concentrations (not shown). Under these conditions, an increasing fraction of the primary production remains ungrazed and sinks to the sediment.

The total nitrogen inventory in the sediment was estimated by integrating organic nitrogen, ammonium, and nitrate up to $60 \mathrm{~cm}$ depth (the total sediment depth modeled). This estimate is accurate for the reactive organic matter, which does not penetrate deeper than $15 \mathrm{~cm}$, and for nitrate, which is completely consumed within the upper centimeter of the sediment. In contrast, the ammonium concentration is highest at great sediment depth, and the deeper the integration, the larger the share of total ammonium in the sedimentary nitrogen inventory will become. However, it is reasonable to assume that 
Fig. 7 A Benthic mineralization as a percentage of total mineralization. B Percentage of total nitrogen residing in the upper $60 \mathrm{~cm}$ of the sediment. C Total sedimentary denitrification. D Annual percentage removal of total (benthic + pelagic) nitrogen due to sedimentary denitrification
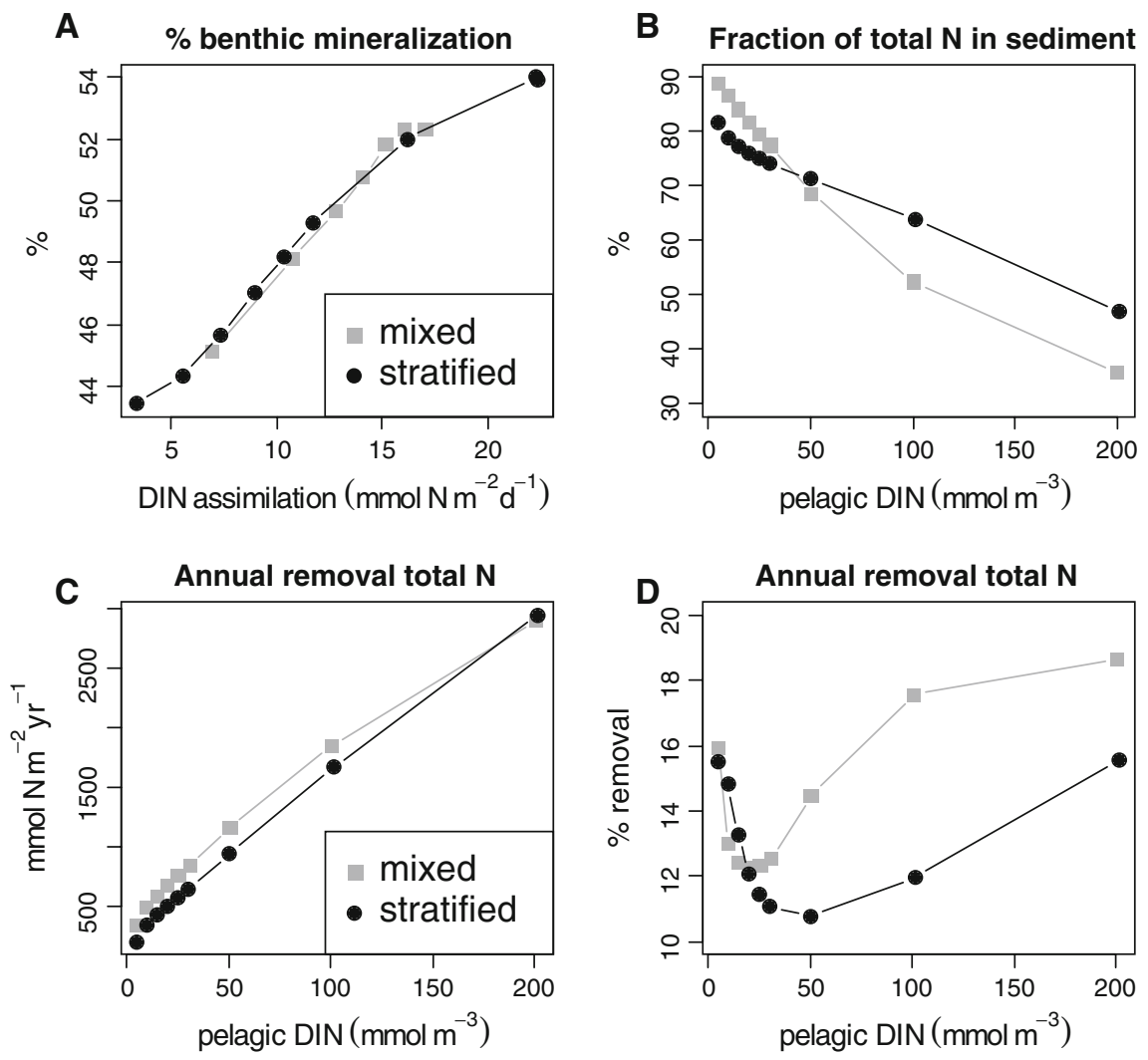

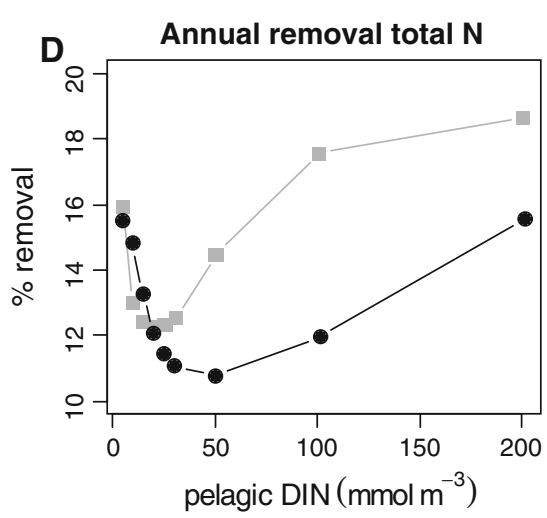

deeply buried ammonium $(>60 \mathrm{~cm})$ will not influence the dynamics of the overlying waters and can therefore be ignored. Moreover, most of the sedimentary nitrogen resides in the organic nitrogen fraction, only $2.5-2.7 \%$ (mixed) or $2.2-2.6 \%$ (stratified) of sediment nitrogen consists of ammonium; nitrate contributes a negligible amount. Thus, even if ammonium was to be integrated to one meter depth or deeper, this would not have a large impact on the estimated sediment inventory.

Total nitrogen in the sediment ranges from 2000 to $5000 \mathrm{mmol} \mathrm{N} \mathrm{m}^{-2}$ in the mixed-case scenario and from 1000 to $9000 \mathrm{mmol} \mathrm{N} \mathrm{m}^{-2}$ below stratified waters (not shown). When expressed as a percentage of the total (i.e., pelagic + benthic) nitrogen inventory, the importance of the sediment as a reservoir of reactive nitrogen becomes evident (Fig. 7B). At oligotrophic to moderately eutrophic conditions (winter DIN $<50 \mathrm{mmol} \mathrm{m}^{-3}$ ), 70-90\% of all nitrogen resides in the sediment, and this lowers consistently with increasing eutrophication. However, even at the most eutrophic conditions, $38-48 \%$ of all nitrogen is found in the sediment.
In both types of sediments, anoxic processes prevail; the contribution to total mineralization varied from 63 to $88 \%$ under a stratified water column, and from 70 to $82 \%$ under a mixed water column (not shown). The contribution of sedimentary denitrification is also similar in both cases (stratified: $8-15 \%$; mixed: $7-20 \%$, not shown), although the source of nitrate differed greatly. In the well-mixed case, denitrification was $100 \%$ fueled by in situ nitrification of ammonium produced during mineralization, except at the highest DIN concentrations (winter DIN $>100 \mathrm{mmol} \mathrm{m}^{-3}$ ), when nitrate from the overlying water also fluxed into the sediment (not shown). In contrast, for sediments underlying stratified water, the influx of bottom-water nitrate which builds up below the thermocline (Figs. 3D, 4B) is much more important. In this case, the contribution of denitrification supported by nitrification declined quasiexponentially from $100 \%$ at the most oligotrophic conditions to $<20 \%$ at pelagic DIN concentrations of $50 \mathrm{mmol} \mathrm{m}^{-3}$ (not shown). The relative contributions of the different mineralization pathways in this model compare well with literature data, which show 
a more than $50 \%$ contribution of anoxic pathways in shallow sediments, and a share between 0 and $20 \%$ for the denitrification (e.g., Burdige, 2006).

The importance of the denitrification process for the nitrogen cycling in the two conditions is represented in Fig. 7C, D. The sedimentary losses vary from 200 to $3000 \mathrm{mmol} \mathrm{N} \mathrm{m}^{-2} \mathrm{yr}^{-1}$ (Fig. 7C), which is $10-20 \%$ of the total nitrogen per year (Fig. 7D). When expressed as a function of pelagic nitrogen, the removal varies from $25 \%$ (most eutrophic) to $140 \%$ (oligotrophic) per year (not shown). The denitrification process is more important under the well-mixed condition compared to the stratified condition because primary production, as well as benthic mineralization, is higher here (except in the most eutrophic conditions), while the contribution of denitrification to total sediment mineralization is comparable.

Nutrient reduction scenarios

Nutrient concentrations in an open system result from the balance of input and output processes. In the model described here, the output and input are, respectively, the sedimentary denitrification and the flux that compensates the losses due to denitrification (see Material and Methods, submodel coupling). Although this model approach is very simple, it closely mimics the overall nitrogen balance in shelf ecosystems, where nitrate input from external sources is balanced by denitrification (Middelburg \& Soetaert, 2005).

If the nitrogen loading (input) to the water column is altered, then the system dynamics will change until the denitrification again balances the nitrogen addition, and steady-state seasonal dynamics are restored. The magnitude of denitrification depends on the nutrient concentrations in the overlying water and the rate of sedimentary organic matter mineralization, which in turn depends on the water-column nitrogen concentration. Thus, if the nutrient inputs to the system are altered, the steady-state nutrient concentrations will also be altered. Figure 8 is essentially a redrawing of Fig. 7C, but now the annual mean DIN concentration in the water column has been plotted as a function of the net nitrogen input to the system. Note that this net input is expressed per square meter of horizontal surface, thus to convert to whole ecosystem inputs, this value should be multiplied by the mean surface area of the system.
Several interesting aspects can be deduced from Fig. 8. First, as total denitrification is greater in the well-mixed scenario, total pelagic nitrogen concentrations are greater, up to about $10 \mathrm{mmol} \mathrm{m}^{-3}$, in stratified compared to well-mixed conditions, for the same nitrogen loading. Second, the effect of a certain reduction in the nitrogen load on the pelagic nitrogen concentration can be estimated. For instance, a loading of $3000 \mathrm{mmol} \mathrm{N} \mathrm{m} \mathrm{yr}^{-1}$ results in a mean pelagic DIN concentration of $\sim 200 \mathrm{mmol} \mathrm{m}^{-3}$, while at half the loading, the DIN concentration becomes 87 and $72 \mathrm{mmol} \mathrm{\textrm {m } ^ { - 3 }}$ under stratified and mixed conditions, respectively, a reduction of 57 and $64 \%$ of the original concentration. Halving the DIN loading of $1000 \mathrm{mmol} \mathrm{N} \mathrm{m}^{-2} \mathrm{yr}^{-1}$ will ultimately reduce the total DIN concentration from 52 to $22 \mathrm{mmol} \mathrm{m}^{-3}$ (a reduction of 58\%) for stratified conditions and from 38 to $12 \mathrm{mmol} \mathrm{m}^{-3}$ (68\%) for well-mixed conditions.

Third, Fig. 9 illustrates the results from a nutrient reduction scenario for the mixed case (Fig. 9A) and the stratified (Fig. 9B) condition. Starting from a water column with an average DIN concentration of $30 \mathrm{mmol} \mathrm{m}^{-3}$, the nutrient inputs (estimated as the annually averaged denitrification under equilibrium) were halved, and the model is run for 20 years under these altered inputs. There is a strong decline in the nutrient concentration at the onset of the nutrient loading reduction, but this is subsequently attenuated.

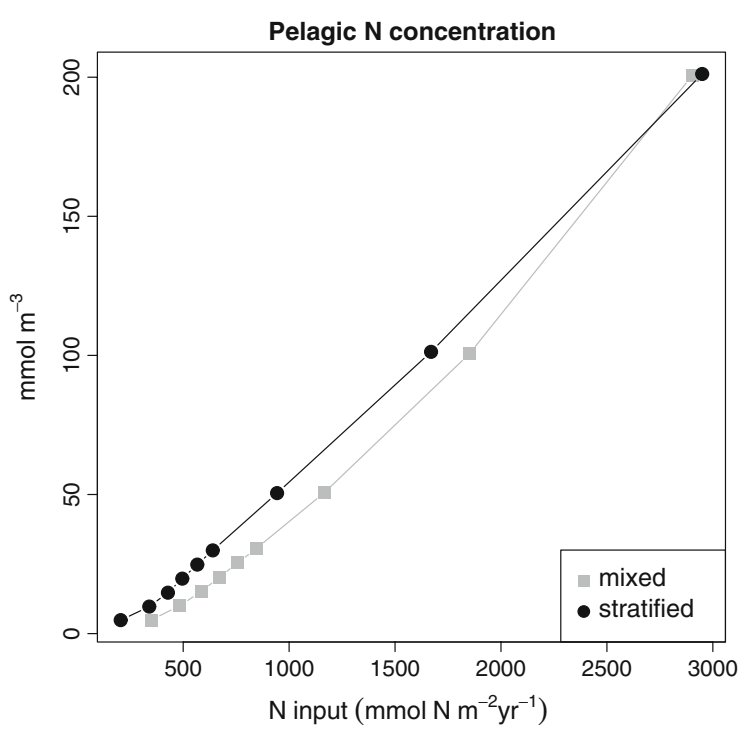

Fig. 8 Pelagic nitrogen concentration as a function of total nitrogen input 
Fig. 9 Pelagic DIN concentration versus time (20 years) for the $50 \%$ reduction scenario in the mixed (A) and stratified (B) case. The thick line shows the annual-averaged concentrations versus time. The thin horizontal line denotes the ultimate equilibrium concentration
A

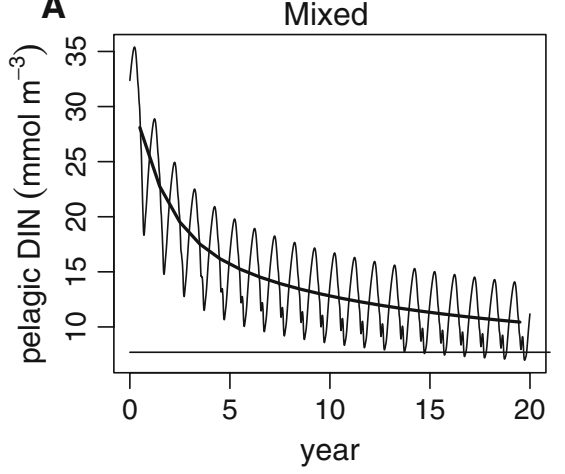

B

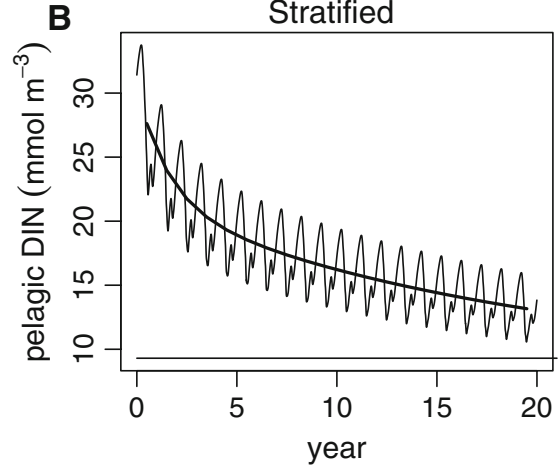

Even after the system has been subjected to the reduced nutrient inputs for 20 years, the new equilibrium DIN concentration is not yet attained, but is still $2.7 \mathrm{mmol} \mathrm{m}^{-3}$ (mixed) and $3.9 \mathrm{mmol} \mathrm{m}^{-3}$ (stratified) above those values. At that time, only 34\% (stratified) and 37\% (mixed) of the total system nitrogen loss has occurred in the water column. Most of the nitrogen has been lost from the sediment organic nitrogen (60 and 56\% for stratified and mixed scenarios, respectively). Desorption of ammonium (5 and 6\%, respectively) and loss of dissolved ammonium from the sediment (1\% each) contribute only marginally to system losses.

\section{Discussion}

Estimates of denitrification rates are often lower where bottom waters become anoxic (Kemp et al., 1990; Childs et al., 2002). However, many denitrification measurements are performed in shallower regions where anoxia coincides with low nitrate concentrations. In these environments, denitrification is impeded by nitrate limitation, due to the absence of nitrification (caused by oxygen deficiency) and low concentrations of bottom-water nitrate. Compared to these situations, the simulations reported here are somewhat atypical: as the bottom water is too deep to allow algal growth, high nitrate concentrations below the mixed-layer depth are generated. Note that the modeled increase of nitrate up to about $20 \mathrm{mmol} \mathrm{m}^{-3}$ (Fig. 3D) corresponds well with findings in other coastal areas, for example, in the German Bight during the 1980s (Brockmann et al., 1990).

Consistent with the above-mentioned measurements, this model predicts (slightly) lower nitrogen removal efficiencies under thermal stratification, albeit for different reasons. In both stratified and well-mixed conditions, the sediment functions similarly with respect to benthic removal of reactive nitrogen: compared to total sediment mineralization, the relative importance of denitrification in both scenarios is similar and varies between $8-15 \%$ and $7-20 \%$ for the stratified and mixed case, respectively. The slightly lower overall removal during stratification (Fig. 7C) arises because, for similar pelagic DIN concentrations, algal production is lower (Fig. 5A); therefore, the supply of organic matter and thus sedimentary mineralization and denitrification are also lower.

That the denitrification is so similar under the very different bottom-water conditions in the oxic and anoxic environments relates to the contrasting sediment communities. The organic-rich sediments underlying oxic bottom waters (as in the well-mixed scenario) are populated by long-lived, relatively large benthic animals. By ventilating their burrows, they facilitate oxygen transfer to the sediment (Aller, 1980; Meysman et al., 2006), which enhances the reoxidation of ammonium (nitrification) and promotes denitrification of the nitrate formed in situ. In contrast, sediments exposed to low-oxygen or anoxic bottom waters are either devoid of life or populated by smaller, opportunistic species that do not ventilate the sediments. In the absence of oxygen, nitrate that has built up in the bottom water is the only source for sedimentary denitrification, but the rate at which this nitrate can flux into the sediment is limited due to the reduced sediment-water exchange rates. The overall effect of these two types of benthic ecosystems is that denitrification contributes similarly and significantly to coastal nitrogen cycling under both oxic and anoxic conditions. 
Marine systems are essentially three-dimensional environments, driven by inflows and outflows of pelagic constituents (via currents and turbulence) and by internal biogeochemical processes. When the external driving variables remain constant over a sufficiently long period of time, or are recurring with a certain (e.g., annual) periodicity, steady-state seasonal dynamics will evolve, whereby inputs exactly balance outputs. For nitrogen, this means that the net input of external nitrogen, resulting from threedimensional hydrodynamics, will balance the sedimentary denitrification, by far the most important, if not the only, loss term. In order to obtain such a steady-state by dynamically running a model, however, is computationally costly. This is especially true when sedimentary processes are explicitly modeled, due to the very long time scales involved; the residence time of the less labile organic matter in the sediment is of the order of tens to hundreds of years, and it will take several times this amount of time before the steady-state will be achieved. Nevertheless, as this fraction of organic matter plays an important role in a system's resilience, it cannot simply be ignored (Soetaert et al., 2000).

Whereas it is now possible to couple relatively complex sediment models that accurately describe the benthic biogeochemical complexity to water column models, this is only rarely done in practice (Soetaert et al., 2000—but see Luff \& Moll, 2004 for an exception). Moll \& Radach (2003) reported that most of the three-dimensional models applied to the North Sea either included no benthic module or only a crude parameterization of the benthic-pelagic coupling. The potential artifacts that this omission or simplification may create, and some simple models describing sediment-water interactions, have been discussed by Soetaert et al. (2000).

In the modeling application described here, the three dimensions were compressed into one vertical dimension. Due to that, the ability to explicitly describe the net import of new, external nitrogen due to hydrodynamic processes is lost, such that it has to be imposed. The omission of seasonality in hydrodynamic inputs, however, allows the emphasis to shift toward a more detailed representation of benthic processes, and thus to assess their impact on ecosystem functioning.

If it is assumed that nitrogen losses are immediately compensated by lateral inputs, the model is a computationally very effective tool for estimating ecosystem dynamics in which pelagic and benthic processes are in (a recurrent) equilibrium. By applying the model over a eutrophication gradient, a relationship is obtained between the net lateral input of external nitrogen and the pelagic DIN concentration, representing a proxy for the eutrophication status of shallow-water systems (Fig. 8).

Comparing the results for stratified waters, where net removal is lower, with the well-mixed scenario shows that, as less nitrogen is removed, total pelagic nitrogen concentrations are higher at the same loadings. At intermediate inputs, the difference is largest, with pelagic DIN concentrations up to about $10 \mathrm{mmol} \mathrm{m}{ }^{-3}$ higher for the same nitrogen loading (Fig. 8). This supports the idea that the more efficient nitrogen regeneration under water-column anoxia promotes the eutrophication potential of the waters and vice versa, as has been postulated for nitrogen (Childs et al., 2002) and phosphorus (Ingall \& Jahnke, 1997; Wallmann, 2003).

The long-term effect of a reduction in nitrogen load on the pelagic nitrogen concentration can also be estimated. Depending on the initial conditions, a 50\% reduction in loadings ultimately results in new equilibrium conditions which have more than a proportionate reduction (57-68\%) in pelagic DIN concentration. The benefit is slightly larger at lower initial eutrophication conditions (Fig. 8).

Of the studies that model the response of shallow systems to oligotrophication (e.g., Skogen et al., 2004), few include the detailed response of the sediment (Lancelot \& Billen, 1985). In accordance with the latter study, the model simulations here of $50 \%$ reductions in nutrient loading clearly show that internal loading of nitrogen from the sediments needs to be considered when restoring these systems from severe eutrophication. The storage of nutrients in the sediments significantly delays the system's recovery, but significant changes in the eutrophication status already take place at a time scale of 10-20 years. A similar delay in system recovery to reduced phosphorus loading by internal loading in the sediment has been shown for certain lakes (Jeppesen et al., 2005).

Finally, although the modeling results presented here are hopefully informative and thought provoking, the authors do not expect or pretend them to be generally valid. By restricting the model to a 50-m- 
deep water column, by using specific parameter values focusing on nitrogen (excluding phosphorus and silicate), and by omitting certain processes that may be important in some regions (i.e., $\mathrm{N}_{2}$ formation in the water column), the model mainly serves to demonstrate the importance of benthic-pelagic coupling under these specific conditions. However, it is hoped that this study will provide impetus for the inclusion of more detail on the benthic compartment when modeling eutrophication and oligotrophication in shallow waters, in particular regarding the intimate feedbacks between nutrient regeneration efficiency and benthic animals.

\section{Conclusions}

In shallow areas, sediments have a large effect on water-column nitrogen dynamics. They determine the ultimate DIN concentration in the water column in winter and slow down the long-term effects of nutrient reduction scenarios. In order to realistically reproduce these processes in simulation models, an adequate representation of sediment-water exchange is necessary.

Acknowledgments The authors thank the organizing committee, and especially Jesper H. Andersen, for inviting them to The International Symposium on Research and Management of Eutrophication in Coastal Ecosystems. This is publication no. 4085 of the Netherlands Institute of Ecology, Centre for Estuarine and Marine Ecology (NIOO-CEME). Two anonymous reviewers are thanked for constructive criticism.

Open Access This article is distributed under the terms of the Creative Commons Attribution Noncommercial License which permits any noncommercial use, distribution, and reproduction in any medium, provided the original author(s) and source are credited.

\section{References}

Aller, R. C., 1980. Quantifying solute distribution in the bioturbated zone of marine sediments by defining an average microenvironment. Geochimica Et Cosmochimica Acta 44: $1955-1965$.

Alongi, D. M., 2005. Ecosystem types and processes. In Robinson, A. R. \& K. Brink (eds), The Sea, Vol. 13, The Global Coastal Ocean: Multiscale Interdisciplinary Processes. Harvard University Press, Cambridge: 317-351.

Boudreau, B. P., 1996. Diagenetic Models and Their Implementation. Modelling Transport and Reactions in Aquatic Sediments. Springer, Berlin.
Brockmann, U. H., R. W. P. M. Laane \& H. Postma, 1990. Cycling of nutrient elements in the North Sea. Netherlands Journal of Sea Research 26: 239-264.

Brown, P. N., G. D. Byrne \& A. C. Hindmarsh, 1989. VODE: a variable coefficient ODE solver. SIAM Journal of Scientific and Statistical Computing 10: 1038-1051.

Burdige, D. J., 2006. Geochemistry of Marine Sediments. Princeton University Press, Princeton.

Cerco, C. F. \& T. Cole, 1993. 3-Dimensional eutrophication model of Chesapeake Bay. Journal of Environmental Engineering-ASCE 119: 1006-1025.

Chen, C., D. A. Wiesenburg \& L. Xie, 1997. Influences of river discharge on biological production in the inner shelf: a coupled biological and physical model of the LouisianaTexas shelf. Journal of Marine Research 55: 293-320.

Childs, C. R., N. N. Rabalais, R. E. Turner \& L. M. Proctor, 2002. Sediment denitrification in the Gulf of Mexico zone of hypoxia. Marine Ecology Progress Series 240: 285-290.

Christensen, J. P., 1994. Carbon export from continental shelves, denitrification and atmospheric carbon dioxide. Continental Shelf Research 14: 547-576.

de Bie, M. J. M., J. J. Middelburg, M. Starink \& H. J. Laanbroek, 2002. Factors controlling nitrous oxide at the microbial community and estuarine scale. Marine Ecology Progress Series 240: 1-9.

Gaspar, P., Y. Grégoris \& J.-M. Lefevre, 1990. A simple eddykinetic energy model for simulations of the oceanic vertical mixing: tests at Station Papa a long-term upper ocean study site. Journal of Geophysical Research 95(C9): 16179-16193.

Heip, C. H. R., N. K. Goosen, P. M. J. Herman, J. Kromkamp, J. J. Middelburg \& K. Soetaert, 1995. Production and consumption of biological particles in temperate tidal estuaries. Oceanography and Marine Biology-An Annual Review 33: 1-149.

Ingall, E. \& R. Jahnke, 1997. Influence of water-column anoxia on the elemental fractionation of carbon and phosphorus during sediment diagenesis. Marine Geology 139: 219229.

Jeppesen, E., M. Sondergaard, J. P. Jensen, K. E. Havens, O. Anneville, L. Carvalho, M. F. Coveney, R. Deneke, M. T. Dokulil, B. Foy, D. Gerdeaux, S. E. Hampton, S. Hilt, K. Kangur, J. Kohler, E. H. H. R. Lammens, T. L. Lauridsen, M. Manca, M. R. Miracle, B. Moss, P. Noges, G. Persson, G. Phillips, R. Portielje, C. L. Schelske, D. Straile, I. Tatrai, E. Willen \& M. Winder, 2005. Lake responses to reduced nutrient loading - an analysis of contemporary long-term data from 35 case studies. Freshwater Biology 50: 1747-1771.

Joint, I. \& A. Pomroy, 1993. Phytoplankton biomass and production in the southern North Sea. Marine Ecology Progress Series 99: 169-182.

Jørgensen, B. B., 1983. Processes at the sediment-water interface. In Bolin, B. \& R. B. Cook (eds), The Major Biogeochemical Cycles and their Interactions. SCOPE, Stockholm: 477-515.

Josefson, A. B. \& B. Widbom, 1988. Differential response of benthic macrofauna and meiofauna to hypoxia in the Gullmar-Fjord basin. Marine Biology 100: 31-40.

Justic, D., N. N. Rabalais \& R. E. Turner, 2005. Coupling between climate variability and coastal eutrophication: 
evidence and outlook for the northern Gulf of Mexico. Journal of Sea Research 54: 25-35.

Kemp, W. M., P. Sampou, J. Caffrey, M. Mayer, K. Henriksen \& W. R. Boynton, 1990. Ammonium recycling versus denitrification in Chesapeake Bay sediments. Limnology and Oceanography 35: 1545-1563.

Kemp, W. M., W. R. Boynton, J. E. Adolf, D. F. Boesch, W. C. Boicourt, G. Brush, J. C. Cornwell, T. R. Fisher, P. M. Glibert, J. D. Hagy, L. W. Harding, E. D. Houde, D. G. Kimmel, W. D. Miller, R. I. E. Newell, M. R. Roman, E. M. Smith \& J. C. Stevenson, 2005. Eutrophication of Chesapeake Bay: historical trends and ecological interactions. Marine Ecology Progress Series 303: 1-29.

Kriest, I. \& G. T. Evans, 1999. Representing phytoplankton aggregates in biogeochemical models. Deep-Sea Research I 46: 1841-1859.

Kuypers, M. M. M., G. Lavik, D. Woebken, M. Schmid, B. M. Fuchs, R. Amann, B. B. Jørgensen \& M. S. M. Jetten, 2005. Massive nitrogen loss from the Benguela upwelling system through anaerobic ammonium oxidation. Proceedings of the National Academy of Sciences of the United States of America 102: 6478-6483.

Lancelot, C. \& G. Billen, 1985. Carbon-nitrogen relationship in nutrient metabolism of coastal marine ecosystem. Advances in Aquatic Microbiology 3: 263-321.

Luff, R. \& A. Moll, 2004. Seasonal dynamics of the North Sea sediments using a three-dimensional coupled sedimentwater model system. Continental Shelf Research 24: 1099-1127.

Meysman, F. J. R., O. Galaktionov, B. Gribsholt \& J. J. Middelburg, 2006. Bioirrigation in permeable sediments: advective pore water flow induced by burrow ventilation. Limnology and Oceanography 51: 142-156.

Middelburg, J. J. \& K. Soetaert, 2005. The role of sediments in shelf ecosystem dynamics. In Robinson, A. R. \& K. Brink (eds), The Sea, Vol. 13, The Global Coastal Ocean Multiscale Interdisciplinary Processes. Harvard University Press, Cambridge: 353-373.

Middelburg, J. J., K. Soetaert, P. M. J. Herman \& C. H. R. Heip, 1996. Denitrification in marine sediments: a model study. Global Biogeochemical Cycles 10: 661-673.

Middelburg, J. J., K. Soetaert \& P. M. J. Herman, 1997. Empirical relationships for use in global diagenetic models. Deep-Sea Research I 44: 327-344.

Middelburg, J. J., C. M. Duarte \& J. P. Gattuso, 2005. Respiration in coastal benthic communities. In del Giorgio, P. A. \& P. J. B. Williams (eds), Respiration in Aquatic Ecosystems. Oxford University Press, New York: 206224.

Moll, A. \& G. Radach, 2003. Review of three-dimensional ecological modelling related to the North Sea shelf system-Part 1: models and their results. Progress in Oceanography 57: 175-217.

Naqvi, S. W. A., R. J. Noronha \& C. V. G. Reddy, 1982. Denitrification in the Arabian Sea. Deep-Sea Research A 29: 459-469.

Officer, C. B., R. B. Biggs, J. L. Taft, L. E. Cronin, M. Tyler \& W. R. Boynton, 1984. Chesapeake Bay anoxia: origin, development, and significance. Science 223: 22-27.
Otto, L., J. T. F. Zimmerman, G. K. Furnes, M. Mork, R. Saetre \& G. Becker, 1990. Review of the physical oceanography of the North Sea. Netherlands Journal of Sea Research 26: 161-238.

Rabalais, N. N., 2005. Eutrophication. In Robinson, A. R. \& K. Brink (eds), The Sea, Vol. 13, The Global Coastal Ocean: Multiscale Interdisciplinary Processes. Harvard University Press, Cambridge: 821-866.

Rabalais, N. N., R. E. Turner \& W. J. Wiseman, 2002. Gulf of Mexico hypoxia, aka 'The dead zone'. Annual Review of Ecology and Systematics 33: 235-263.

Rabouille, C., F. T. Mackenzie \& L. M. Ver, 2001. Influence of the human perturbation on carbon, nitrogen, and oxygen biogeochemical cycles in the global coastal ocean. Geochimica Et Cosmochimica Acta 65: 3615-3641.

Skogen, M. D., H. Soiland \& E. Svendsen, 2004. Effects of changing nutrient loads to the North Sea. Journal of Marine Systems 46: 23-38.

Soetaert, K., P. M. J. Herman \& J. J. Middelburg, 1996. A model of early diagenetic processes from the shelf to abyssal depths. Geochimica Et Cosmochimica Acta 60: 1019-1040.

Soetaert, K., J. J. Middelburg, P. M. J. Herman \& K. Buis, 2000. On the coupling of benthic and pelagic biogeochemical models. Earth-Science Reviews 51: 173-201.

Soetaert, K., P. M. J. Herman, J. J. Middelburg, C. H. R. Heip, C. L. Smith, P. Tett \& K. Wild-Allen, 2001. Numerical modelling the shelf break ecosystem: reproducing benthic and pelagic measurements. Deep-Sea Research II 48: 3141-3177.

Soetaert, K., V. deClippele \& P. Herman, 2002. Femme, a flexible environment for mathematically modelling the environment. Ecological Modelling 151: 177-193.

Soetaert, K., J. J. Middelburg, C. Heip, P. Meire, S. Van Damme \& T. Maris, 2006. Long-term change in dissolved inorganic nutrients in the heterotrophic Scheldt estuary (Belgium, the Netherlands). Limnology and Oceanography 51: 409-423.

Tett, P. \& M. R. Droop, 1988. Cell quota models and planktonic primary production. In Wimpenny, J. W. T. (ed.), CRC Handbook of Laboratory Model Ecosystems for Microbial Ecosystems. CRC Press, Florida: 177-233.

Van Cappellen, P. \& R. A. Berner, 1988. A mathematical model for the early diagenesis of phosphorus and fluorine in marine sediments-apatite precipitation. American Journal of Science 288: 289-333.

van Raaphorst, W. \& V. N. de Jonge, 2004. Reconstruction of the total $\mathrm{N}$ and $\mathrm{P}$ inputs from the Ijsselmeer into the western Wadden Sea between 1935 and 1998. Journal of Sea Research 51: 109-131.

Wallmann, K., 2003. Feedbacks between oceanic redox states and marine productivity: a model perspective focused on benthic phosphorus cycling. Global Biogeochemical Cycles 17: art. No. 1084.

Wollast, R., 1998. Evaluation and comparison of the global carbon cycle in the coastal zone and in the open ocean. In Brink, K. H. \& A. R. Robinson (eds), The Sea, The Global Coastal Ocean, Processes and Methods. Wiley, New York: 213-252. 